\title{
Identifying the Merits of Sophomore Involvement in New Student Orientation
}

\author{
Katie Branch, Adrienne Taylor, and James Douglas
}

Extended orientation courses for first-year students, as well as mentoring programs, are prevalent in higher education in the United States (Barefoot \& Gardner, 1993; Ender $\&$ Newton, 2000). These courses are often referred to as freshman, first-year, or new student seminars. The purpose of such seminars typically is to provide an orientation to the college or university that is holistic in content, while utilizing developmentallyappropriate educational processes (Barefoot \& Gardner, 1993).

For many traditional-aged first-year students, college is a place away from home and family; it is most commonly a new, exciting, challenging, and yet scary place. Incorporating student mentors into new student seminars can help ease the transition into the collegiate environment. King (1995) wrote

The freshman seminar class becomes a 'safe' place to raise questions and to express concerns. The power of this group experience where students discover other freshmen have similar questions and fears and the relationship with the instructor/mentor cannot be overestimated...QQuite often we find that freshmen feel more comfortable asking questions of fellow students who have been in their shoes than they do talking to faculty. (p. 46-47)

Utilizing second-year students as peer leaders in first-year student seminars can benefit both the first-year students and these sophomores. As Pattengale and Schreiner (2000) noted, sophomores are often the group of students on campus who are targeted least for intentional, individual, or programmatic-level interventions. This is especially unfortunate because second-year students may be experiencing aspects of a developmental phenomena referred to as the "sophomore slump" (Bolvin, Fountain, \& Baylis, 2000; Gohn, Swartz, \& Donnelly, 2001; Lemons \& Richmond, 1987; Richmond $\&$ Lemons, 1985). This period is characterized by disappointment and dissatisfaction with the collegiate experience, a lack of social and academic integration, and confusion about personal attributes and career interests (Anderson \& Schreiner, 2000; Lemons \& Richmond, 1987; Tinto, 1993). Pattengale and Schreiner (2000) pointed out

If the goal is to facilitate the learning process to equip students for a

Katie Branch is an Associate Professor in Human Development and Family Studies at the University of Rhode Island. Adrienne Taylor is an Assistant Director of Student Life for Judicial and Commuter Affairs at the University of Rhode Island and the former Sophomore Class Advisor at Salve Regina University. James R. Douglas is an Academic Advisor in the McAnulty College of Liberal Arts at Duquesne University. 
lifetime of learning, educators should be alarmed if sophomores are falling into a curricular and programmatic gap-often with memories of special first-year initiatives and knowledge of major classes enjoyed by their junior and senior colleagues." (p. vi)

Student involvement is an important aspect of the holistic and developmental environments of first-year seminars. This involvement can be expanded when sophomores are included as peer educators and leaders. Schlossberg, Lynch, and Chickering's (1989) ideas on mattering and marginality emphasize the importance of students feeling part of the institution and having a sense of belonging in their collegiate community. Mattering is defined as "the belief people have, whether right or wrong that they matter to someone else, that they are the object of someone else's attention, and that others care about them and appreciate them" (Schlossberg, Lynch, \& Chickering, 1989 , p. 21). When students feel a sense of belonging and believe they matter to their institution, satisfaction, retention and academic success can increase. On the other hand, "students have feelings of marginality when they do not think they matter; they feel out of place, alienated, not central, lack connections, or feel as if they do not belong" (Anchors, Branch Douglas, \& Kasper, 1993, p. 464). First-year student seminars have been implemented at colleges and universities as a way to increase students' sense of mattering and decrease feelings of marginality. Adding sophomores as mentors to these new student seminars also can enhance their sense of mattering (Anderson \& Schreiner, 2000).

Based on observations and research about the on-going transition process to college, Salve Regina University, a Catholic co-educational liberal arts institution located in the Northeast, developed a Sophomore Mentor Program (SMP) to coincide with its first-year student seminar. This program attempted to increase second-year students' academic and personal success, and cultivate an on-going sense of belonging to the institution. In addition, the seminar sections demonstrated collaborative learning environments in which first-year students could develop potentially long lasting, positive relationships with a peer mentor, faculty member, and professional staff member from the institution.

\section{Sophomore Mentor Program}

Salve Regina University has been offering a first-year student seminar called the New Student Seminar (NSS) since 1988. The SMP, piloted during the Fall Semester 1998, consisted of 30 sophomores and a professional staff member who served as the program coordinator. Each sophomore mentor went through an application process, with 45 sophomores applying and 32 originally accepted, to help facilitate sections of the NSS. Along with co-facilitating the NSS sections, the mentors met bi-weekly, in groups of 10 students each, in a class session with the SMP coordinator. Mentors received one academic credit for their contributions to the NSS and for their involvement in the SMP course.

With a class of 450 incoming students for the 1998-1999 academic year, the NSS was divided into 30 different sections with 15 new students assigned to each in 
accordance with their intended majors. Seminars met for 50 minutes once a week for 14 weeks during the fall semester, and three times during the spring semester for class follow-up. During the14 weeks in the fall, seminars met both as small groups for discussion and also in large groups for four special topic presentations. In keeping with desires for collaboration between academic and student affairs, each section was facilitated by a faculty member, a professional staff member, and a sophomore mentor.

The role of the sophomore mentor was to serve as a resource to freshman enrolled in the NSS and to assist in their transition to college. Expectations for the sophomores included demonstrating consistent concern for the academic and social integration of the students enrolled in the seminar, serving as a role model, and making referrals to appropriate university and community resources when necessary.

With the development of the SMP, academic and student life administrators hoped that the mentors would have positive, growth-oriented experiences in both educational and personal areas. To determine what impact, if any, the SMP had on both the students involved as mentors and the new students enrolled in the NSS, assessment measures were implemented that led to an evaluation of the SMP.

\section{Methods}

The primary emphasis of the assessment measures was to determine the impact, if any, that participation in the program had on the sophomore mentors. In addition, it was important to measure what impact, if any, the sophomore mentors inclusion in the NSS had on first-year students. Data were also collected from faculty and professional staff who served as NSS instructors and from the SMP coordinator, the NSS coordinator, and the individual responsible for the academic affairs portion of the NSS. While this article focuses on the data that were collected from the students involved in the 1998-1999 SMP and NSS, findings from faculty and staff were also noted.

\section{Participants}

The student participants in this assessment included 9 sophomores and 15 first-year students. Potential participants were divided into small focus groups with five students invited to attend each session; all but one student arrived for their scheduled focus group sessions. Seven female and two male sophomore mentors participated in their groups. In regard to the 15 freshman participants, nine out-of-state and six in-state students attended five-person focus group meetings. All were 18 years of age, and four were males and eleven were females.

To receive feedback from the faculty and staff facilitators of NSS sections, attempts were made to schedule four focus groups, each consisting of five interviewees. One, five-person staff focus group was conducted. Because of difficulties in finding a common meeting time for the other focus groups, an additional four staff and 10 faculty members provided feedback in hard copy or electronic formats to the same questions asked in the focus group. Individual interviews were conducted with the coordinator of the SMP, the coordinator of the academic affairs portion of the NSS, and the overall 
coordinator of the NSS.

\section{Sampling Process}

Participants were obtained through systematic selection. Ten faculty, 10 staff, and 10 sophomore mentors were selected from a list of the 30 NSS sections. To obtain the first-year student sample, the registrar's office printed out a list of in-state first-year students and a list of out-of-state first-year students. Because the number of out-of-state students was higher than in-state students, fewer names from the in-state group than from the out-of-state group were systematically and proportionately drawn.

Potential participants were sent a memo in both electronic and hard copy formats that explained the study and requested their volunteer assistance. Follow-up phone calls also were made.

\section{Process of Gathering Data}

Data were gathered primarily through using loosely structured questions in each focus group. Questions were tailored to each group of participants and all responses were audiotaped. Each focus group met once for an hour. The following questions were asked in the sophomore mentor focus groups:

1. When you applied to be a sophomore mentor, what were some of the things you expected to gain from this [mentoring] experience? Were your expectations met?

2. As mentors, what do you feel your overall responsibilities should be in the NSS?

3. What are your reactions to the NSS format (having a mentor, staff, and faculty member facilitating the seminar)?

4. What are some of the ways the SMP had an impact on you and the NSS?

5. What changes/adjustments would you recommend for the future NSS in regard to the SMP?

The following questions were asked in the freshman focus groups:

1. What were your overall expectations of the sophomore mentor? Were these expectations met?

2. How would you describe your mentor's involvement/interactions with the students?

3. What was the overall impact of the sophomore mentor in the NSS?

4. What changes/adjustments would you recommend for the future NSS in regard to the SMP?

Staff and faculty were asked the following:

1. What did you hope to see happen to the NSS by incorporating a sophomore mentor into the teaching triad? Did you see this happen? 
2. What do you feel the overall responsibilities of the mentors should be? Do you feel these expectations were met?

3. What are some of the ways the SMP impacted the NSS?

4. What changes/adjustments would you recommend for the future NSS in regard to the SMP?

\section{Data Analysis Process}

After the data were gathered, the audiotapes of the focus group were transcribed by the same individual who conducted the sessions. The hard copy or electronic responses from the faculty and staff who could not attend a focus group session as well as the data collected during the three individual interviews were also entered into a word processing program. Next, a list of participants' responses was developed, with commonalities and differences among these responses being noted. These responses were organized under general categories, with specific examples and quotes explaining and supporting each category. Finally these categories were reviewed by the principle investigators of the study and themes were developed that related to the broad concept of impact on students.

\section{Findings}

Because of the distinctiveness between the themes generated through the sophomore mentor focus groups and the first-year student focus groups, they are reported separately. Themes from the faculty and staff also are identified.

\section{Sophomore Mentor Themes}

Two themes related to the impact of being a sophomore mentor emerged: a) increased development of intrapersonal and interpersonal skills, and b) disappointment and frustration when expectations were not met. The major contributing factor to the enhancement of these skills or to the expressions of these feelings was the degree to which the sophomores were involved, or not involved, in the planning and facilitation of the NSS.

The intrapersonal benefits the students reported gaining as a result of their participation in the SMP included building self esteem, becoming more responsible, and learning how to be a positive role model. Interpersonal development included gaining social, leadership, and public speaking skills as well as an ability to interact with diverse people. One student said "[This was] good training for future careers and parenting in terms of being fair and cool while also showing right from wrong."

Based on unmet expectations, feelings of disappointment and frustration were expressed by approximately half of the students who participated in the sophomore mentor focus groups. Students reported being interested in the SMP because they wanted to help ease the transition for first-year students. For example, one student said, "I wanted to make a positive difference in the freshman's experiences at Salve." Another mentor said, "I hoped to get to know students at a personal level so that they would have 
someone older they could talk to." While half of the mentors in the focus groups said these expectations were not met, half noted that they had made at least some difference in the lives of first-year students.

The primary contributing factor as to whether mentors thought their expectations were met was the degree to which they felt involved as an active member of the seminar's instructional team. In general, all of the mentors expected that they would have had a more active role in the NSS. Mentors who described their role in the seminar as that of taking attendance, passing out handouts, and being a "gopher" were especially disappointed with their experience. Mentors reporting positive relationships with the first-year students in and out of the classroom setting in addition to a much greater sense of having their expectations met noted that they were actively involved in the NSS. One mentor said "I had a lot of student-mentor interaction both in the seminar and out of class."

Overall, mentors seemed both satisfied with their experience and disappointed at the same time. Approximately half of the mentors expressed that they were not happy with their roles in the NSS, primarily because they were not used in a way that met their expectations. Many thought that they would be much more involved in the planning and facilitation of their seminar sections, and that they would be seen more as an equal to the other two instructors. While some of the mentors were disappointed in their experiences, all of the mentors seemed to have gained something positive from their involvement in the SMP.

\section{First-Year Student Themes}

Two themes related to the impact of having a sophomore mentor involved with the NSS emerged during the analysis of data collected in the first-year student focus groups: a) assistance with the adjustment to the university and b) creating a positive climate in the seminar setting. In regard to adjustment, the students thought the sophomore mentors were giving them a "real life" view of the university. In the seminar setting, the presence of the mentor seemed to help the students apply what they were learning to their own situations in addition to creating a positive psychological climate in the classroom.

Gaining a student's perspective of the university contributed to the first-year students' reports that the sophomore mentors helped with their adjustment to the university. More specifically, the first-year students reported their mentors helped them learn about the logistics of policy and procedures on campus as well as how to navigate the social environment. Comments from the first-year students included: "Gave advice on what teachers expect and what the rules are on campus," "[My mentor] showed me where to go to find different resources on campus," "Familiar face on campus to interact with in the dining hall, dorms, and at campus activities," and "Gave social advice on where to go and what to do both on and off campus." Some first-year students reported that the mentors especially were helpful when it came to registration for the following semester's courses. Out-of-state students noted their mentor was key in easing their transition of living in a new state. One such student noted, "having one-on-one interactions, someone to check in on me, and taking part in helping with homesickness 
and giving support" was important. Some students talked about the bond that was formed with their mentors and its continued influence on them. For example, one first-year student reported, "Even though the NSS is over, my mentor is still around campus and interacts with the students from our seminar."

First-year students noted that the inclusion of the mentor in the NSS fostered a comfortable and cohesive learning environment, and thought the mentors made the classroom setting more relaxed and comfortable. "My mentor got the group talking, helped make the atmosphere less awkward," said one student. Another first-year student stated that the mentor "seemed to make other teachers more relaxed especially around subjects such as alcohol use, sexual assault and personal issues." And another said "[The mentor] filled in when faculty and staff were unsure or uncomfortable with the topics."

In general, the mentors impacted first-year student in positive ways. These students developed a relationship with another student on campus who had been through similar experiences at the university during the previous year, and had that same student easily available to them for support and information. Overall, the first-year students found the mentors to be highly valuable resource persons. Lastly, the first-year students indicated that they would have liked more interaction with the mentors both in and out of the classroom, and wanted to hear more from the mentors about their experiences at the university.

\section{Faculty and Staff Themes}

Similar to the first-year students, faculty and staff also recognized that involving sophomores as mentors definitely aided in creating a positive psychological climate in the seminar. One staff member said "[The sophomore mentor] helped make class a seminar through discussion rather than a class being taught as a lecture." One faculty member noted "I noticed more candor than in other seminars that I had in the past." The ability of the sophomore mentors to respond to questions in detail was something especially valued by the faculty and staff instructors. Comments by faculty included "[The mentor] gave students more precise guidance/advise about various things such as socializing, registration, classes," and "Mentors were closer in age to the new students and especially helped with issues of being oriented, residential life, higher education, alternatives to drinking, and the importance of studying." One staff member noted, "I found the age of the mentors very appropriate and effective (as opposed to juniors or seniors being mentors) since they can relate to the students and share information that is useful and fresh."

Having a three-person teaching triad that incorporated a sophomore was disconcerting to some of the faculty and staff. Roles were seen as unclear, and thus, some seminar sections developed a hierarchy of faculty, the staff member, and mentor. Also, the rapport that the sophomores developed quickly with the first-year student was, on occasion, viewed negatively (i.e., described as "undermining" by one faculty instructor), and led one faculty member to suggest that the sophomores not be incorporated into the seminar sections until 4-6 weeks into the semester. 


\section{Disc ussion}

The level and clarity of involvement proved to be critical in augmenting sophomore mentors' intra and interpersonal skill development and their feelings of satisfaction with the mentoring role. The type of sophomore mentor involvement also was key to both the first-year students' and co-instructors' reactions to the NSS experience. Based on the findings, students selected to be sophomore mentors should be involved in nearly all aspects of preparing for the NSS. For this to occur, the new group of sophomore mentors needs to be selected early in the spring semester of their first-year, and it is especially important that the facilitator teams for the NSS sections be established before the spring semester ends to allow the instructors to meet before most students leave campus for the summer. Meeting in the spring to clarify roles in the teaching triad can lead to greater congruence between students' anticipatory expectations and what they may experience as a mentor. Prior to these meetings of the teaching triads, a combined training session for faculty, professional staff, and sophomore mentors should emphasize collaboration and team facilitation, and present a model for how to discuss role expectations among themselves and with the first-year students.

The sophomore mentors who participated in this study indicated they wanted to be involved in selecting and training the next group of mentors. By encouraging this type of involvement, the sophomores could express their opinions on what qualities a mentor should have; talk with the new mentors about their own mentoring experiences; prepare them with skills, information, and activities useful to facilitating the NSS section; and be available to the new mentors if they need information, support, or advice during their time of mentoring.

While some may argue that it does not make any difference whether the mentors involved with the NSS are sophomores, juniors, or seniors, the continuation of using sophomore students is recommended for several reasons. From the data obtained via this study, we found that sophomore students were able to relate to the new students because only a year had passed since they were in their first year. Because the sophomore mentors had just been through the "first-year experience," they were able to provide the students with up-to-date information about the university and college life in general. Most significantly, following the freshman year, sophomores sometimes become the forgotten class. With juniors, there is a focus on different educational opportunities for them to be involved in, such as internships, student teaching, and major selection. Seniors get attention around preparing for graduation and fulfilling degree requirements. Sophomore students can become "lost in the shuffle" without as much attention and opportunities. Having an institutional sponsored sophomore mentor program establishes an arena for these students to be involved in an intentionally-designed campus activity while also building intra and interpersonal skills. 


\section{References}

Anchors, S., Branch Douglas, K., \& Kasper, M. K. (1993). Developing and enhancing Student communities. In R. B. Winston, Jr., S. Anchors, \& Associates (Eds.), Student housing and residential life: A handbook for professionals committed to student development goals (pp. 461-480). San Francisco: Jossey-Bass.

Anderson, E., \& Schreiner, L. A. (2000). Advising for sophomore success. In L. A. Schreiner \& J. Pattengale (Eds.), Visible solutions for invisible students: Helping sophomores succeed (Monograph No. 31) (pp. 55-66). Columbia, SC: University of South Carolina, National Resource Center for the First-Year Experience and Students in Transition.

Barefoot, B., \& Gardner, J. N. (1993). The freshman orientation seminar: Extending the benefits of traditional orientation. In M. L. Upcraft, R. H. Mullendore, B. O. Barefoot, \& D. S. Fidler (Eds.), Designing successful transitions: A guide for orienting students to college (Monograph No. 13) (pp. 141-153). Columbia, SC: University of South Carolina, National Resource Center for the First-Year Experience and Students in Transition.

Bolvin, M., Fountain, G.A., \& Baylis, B. (2000). Meeting the challenges of the sophomore year. In L. A. Schreiner \& J. Pattengale (Eds.), Visible solutions for invisible students: Helping sophomores succeed (Monograph No. 31) (pp. 1-18). Columbia, SC: University of South Carolina, National Resource Center for the FirstYear Experience and Students in Transition.

Ender, S.C., \& Newton, F.B. (2000). Students helping students: A guide for peer education on campus. San Francisco: Jossey-Bass.

Gohn, L., Swartz, J., \& Donnelly, S. (2001). A case study of second year student persistence. Journal of College Student Retention: Research, Theory \& Practice, 2, 271-294.

King, N. S. (1995). Advising and mentoring in the freshman seminar course. In R. E. Glennen \& F. N. Vowell (Eds.), Advising as a comprehensive campus process (NACADA Monograph Series, No. 2) (pp. 45-48). Manhattan, KS: National Academic Advising Association.

Lemons, L. J., \& Richmond, D. R. (1987). A developmental perspective of sophomore slump. NASPA Journal, 24(3), 15-19.

Pattengale, J., \& Schreiner, L. A. (2000). What is the sophomore slump and why should we care? In L. A. Schreiner \& J. Pattengale (Eds.), Visible solutions for invisible students: Helping sophomores succeed (Monograph No. 31) (pp. v-viii). Columbia, SC: University of South Carolina, National Resource Center for the First-Year Experience and Students in Transition.

Richmond, D. R., \& Lemons, L. J. (1985). Sophomore slump: An individual approach to recognition and response. Journal of College Student Personnel, 26, 176-177.

Schlossberg, N. K., Lynch, A. Q., \& Chickering, A. W. (1989). Improving higher education environments for adults: Responsive programs and services from entry to departure. San Francisco: Jossey-Bass.

Tinto, V. (1993). Leaving college: Rethinking the causes and cures of student attrition (2nd ed.). Chicago: The University of Chicago Press. 